\title{
Intravitreal pegaptanib for refractory macular edema secondary to retinal vein occlusion
}

This article was published in the following Dove Press journal:

Clinical Ophthalmology

6 July 2011

Number of times this article has been viewed

Patricia Udaondo ${ }^{1,2}$

Salvador Garcia-Delpech ${ }^{1,3}$

David Salom ${ }^{1,3}$

Maria Garcia-Pous ${ }^{1,3}$

Manuel Diaz-Llopis ${ }^{1,3}$

'Nuevo Hospital Universitario y Politecnico La Fe, Valencia, Spain; ${ }^{2}$ University Cardenal Herrera CEU, Valencia, Spain; ${ }^{3}$ Faculty of Medicine, University of Valencia, Valencia, Spain

Correspondence: Patricia Udaondo C/Botanico 7, pta 14, 46008 Valencia, Spain

Tel +34 647869228

Fax +34963528044

Email patyudaondo@hotmail.com
Purpose: To assess the efficacy of intravitreal Pegaptanib sodium $\left(\right.$ Macugen $\left.^{\circledR}\right)$ injection in the management of refractory macular edema secondary to branch retinal vein occlusion.

Methods: This is a prospective, nonrandomized, interventional case series. Five eyes of five patients with macular edema refractory to either bevacizumab or triamcinolone were treated with intravitreal injection of Pegaptanib sodium.

Results: After three months follow-up, both visual acuity and macular edema, measured by optical coherence tomography and fluorescence angiography, dramatically improved.

Conclusion: Pegaptanib sodium is a safe and efficacy treatment for macular edema secondary to branch retinal vein occlusion.

Keywords: Macugen ${ }^{\circledR}$, BRVO, BCVA, pegaptanib sodium

\section{Introduction}

Branch retinal vein occlusion (BRVO) is a retinal vascular disorder with heterogeneous and complex pathophysiology, commonly affecting elderly patients. Macular edema associated with BRVO is the most common complication and major cause of visual loss in these patients, together with retinal capillary nonperfusion and intraretinal hemorrhages. Different therapies have been proposed to treat the macular edema and improve the visual prognosis of these patients. One of the first widely accepted treatments was the use of a grid pattern laser photocoagulation. ${ }^{1}$ Although many studies demonstrate a statistically significant difference between laser-treated eyes and control-group eyes, visual improvement is limited, and some cases are refractory to laser treatment. ${ }^{2}$

Intravitreal triamcinolone appeared as an alternative treatment to laser. Different studies show an important improvement in visual acuity and macular edema following intravitreal triamcinolone injection, but its effects are limited by many secondary effects and the need of multiple re-injections. ${ }^{3,4}$ Recently, the results of the dexamethasone implant in patients with macular edema due to retinal vein occlusion have been published (GENEVA study); it is concluded that the dexamethasone implant improves the speed and incidence of visual improvement in the treated eyes compared with the sham-treated group. ${ }^{5}$

The agents that inhibit the effects of vascular endothelial growth factor (VEGF), which is involved in pathophysiology of macular edema, ${ }^{6}$ have been used, in many cases in an off-label manner, to treat a variety of ocular diseases, including macular edema secondary to retinal vein occlusion, with satisfactory results. Many studies have found analogous anatomical (measured by optical coherence tomography [OCT]) and visual acuity responses to bevacizumab and ranibizumab (nonselected anti-VEGF therapies) 
with limited adverse side effects in branch and central retinal vein occlusion. ${ }^{7-9}$

In this study, we prospectively studied the efficacy of intravitreal pegaptanib sodium (Macugen ${ }^{\circledR}$ ) by use of OCT (Stratus OCT Model 3000, Humphrey Instruments, Carl Zeiss Inc, Dublin, CA), fluorescein angiography (FA) and bestcorrected visual acuity (BCVA) in five eyes of five patients with refractory macular edema secondary to BRVO, with a mean follow-up of 3 months.

\section{Methods}

Five eyes of five patients with refractory macular edema due to BRVO were enrolled consecutively between May and September 2010 for this study. All patients had a visual acuity of 0.6 or worse, and the evolution of the macular edema was at least 1 year. After the patient signed the corresponding informed consent, intravitreal pegaptanib sodium $0.3 \mathrm{mg} / 90 \mu \mathrm{L}$ injection was performed in the operating room. Topical anesthetic drops, an antibiotic drop, and povidone iodine were administered. Two intravitreal injections of pegaptanib sodium were performed in all cases (5 weeks apart). Patients were followed up for three months after the second injection.

Pre- and post-injection examination included bestcorrected Snellen visual acuity measurement (converted to $\log$ MAR [logarithm of the minimum angle of resolution]), slit-lamp biomicroscopy, Goldmann applanation tonometry, fundus examination, OCT, and FA.

\section{Results}

Five eyes of five patients were included in the study (two men and three women). The mean age of the patients was 69 (range 63-75); the clinical characteristics of the patients included in the study are summarized in Table 1 . The macular edema in all cases had limited or no response to prior treatments with either intravitreal triamcinolone acetonide or bevacizumab injections. The last treatment before receiving the first intravitreal pegaptanib sodium injection was at least 3 months prior in all cases.

Macular edema reduced from $418 \pm 97.7 \mu \mathrm{m}$ to $253 \pm 97.25 \mu \mathrm{m}$, measurable 3 weeks after the first injection of pegaptanib sodium by OCT; the FA also demonstrated an improvement in macular edema, with complete resolution of shunts exudation due to the increase in the vascular permeability after the retinal vein occlusion (Figure 1). The visual acuity improved in all cases by two or more Snellen lines. All the findings, visual acuity and resolution of macular edema in the OCT, remained stable for 3 months after the second injection (Table 1). No side effects associated with pegaptanib sodium injection were found in any case.

\section{Discussion}

As far as we know, our five patients are the first reported cases of refractory macular edema secondary to BRVO treated with pegaptanib sodium with excellent results.

Laser and steroid treatment for patients with BRVO have had statistically significant benefits in terms of retinal thickening and visual acuity, but with several limitations., ${ }^{1,3}$ Laser is not useful in cases of macular nonperfusion and must be deferred when important hemorrhages are present. ${ }^{8}$ Intravitreal triamcinolone injection had demonstrated its usefulness in the treatment of macular edema due to vascular disorders, but multiple side effects have been described associated with it, including cataracts or elevated intraocular pressure. In addition, the durability of this treatment is not clear, and it is necessary to repeat injections. $^{4}$

Anti-VEGF therapy is useful in the treatment of vascular disorders by inactivating the factor involved in the increase of vascular permeability that causes macular edema. On the other hand, the use of intravitreal bevacizumab for BRVO offers significant advantages over triamcinolone and grid-laser

Table I Ophthalmic characteristics of the patients with macular edema secondary to branch retinal vein occlusion treated with intravitreal injection of pegaptanib sodium

\begin{tabular}{|c|c|c|c|c|c|c|c|}
\hline Patient & Age/sex & $\begin{array}{l}\text { Duration of ME } \\
\text { (months) }\end{array}$ & Previous treatment & $\begin{array}{l}\text { BCVA }{ }^{\text {a before }} \\
\text { PSI }\end{array}$ & $\begin{array}{l}\text { MET before } \\
\text { PSI }\end{array}$ & $\begin{array}{l}\text { BCVA }^{a} \text { after } \\
\text { PSI }^{b}\end{array}$ & $\begin{array}{l}\text { MET after } \\
\text { PSI }^{\text {b }}\end{array}$ \\
\hline 1 & $63 / F$ & 12 & 3 bevacizumab & 0.6 & 418 & 0.2 & 236 \\
\hline 2 & $66 / F$ & 14 & 4 bevacizumab & 0.7 & 436 & 0.2 & 224 \\
\hline 3 & $75 / M$ & 13 & 2 triamcinolone & 0.8 & 567 & 0.3 & 260 \\
\hline 4 & $68 / F$ & 16 & $\begin{array}{l}\text { I triamcinolone }+ \\
2 \text { bevacizumab }\end{array}$ & 0.6 & 371 & 0.1 & 189 \\
\hline 5 & $72 / M$ & 15 & 3 bevacizumab & 0.4 & 302 & 0.0 & 178 \\
\hline
\end{tabular}

Notes: ${ }^{a}$ Expressed in the LogMAR (logarithm of the minimum angle of resolution) scale; ${ }^{b}$ After three months follow-up.

Abbreviations: BCVA, best-corrected visual acuity; F, female; M, male; ME, macular edema; MET, macular edema thickness; PSI, pegaptanib sodium injection. 


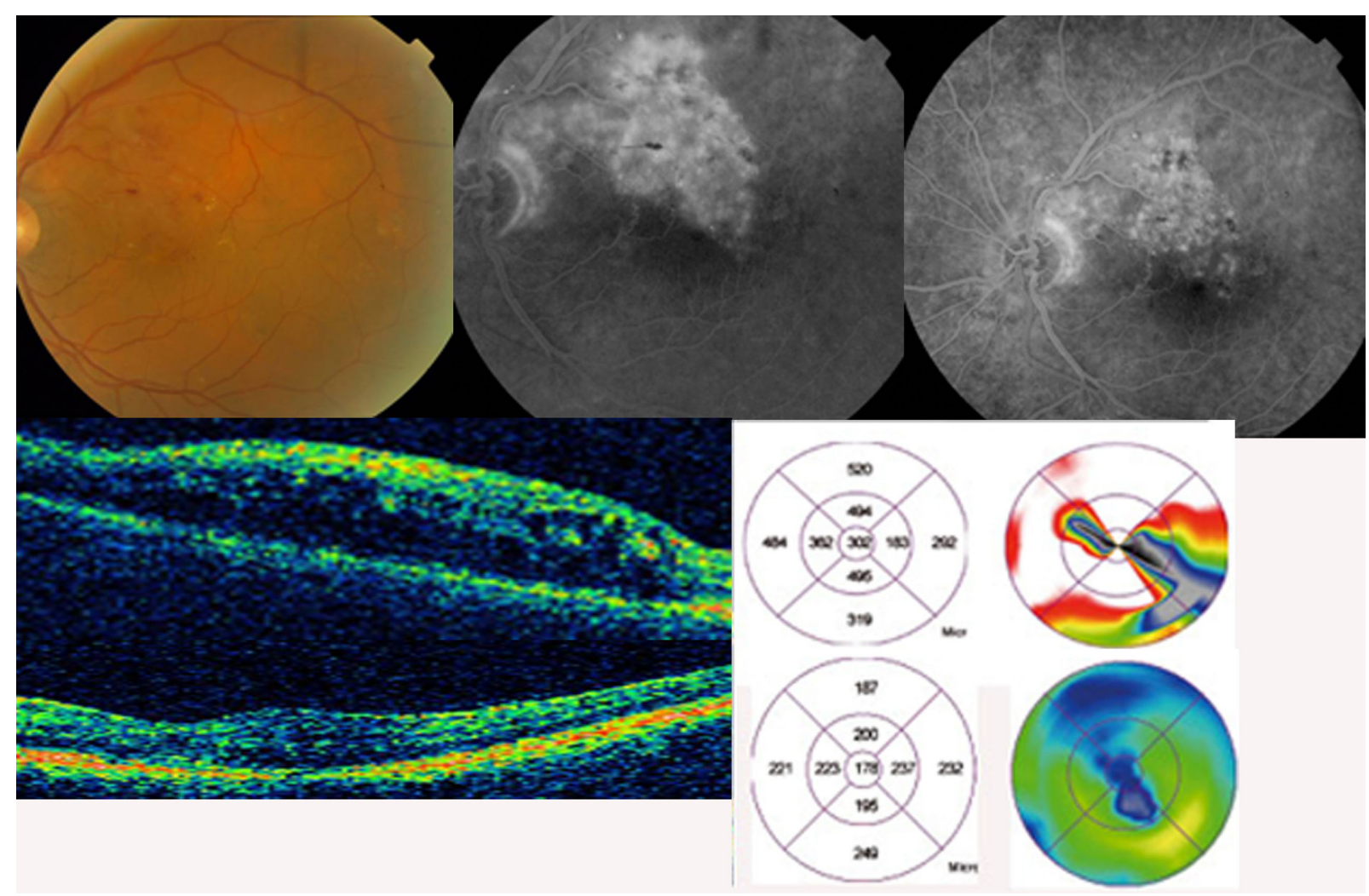

Figure I Funduscopy image, fluorescein angiogram, and optical coherence tomography before and after intravitreal injection of pegaptanib sodium (Macugen ${ }^{\circledR}$. Complete resolution of the macular edema secondary to branch retinal vein occlusion can be seen.

treatment, but in our experience and that of several other studies, multiple injections are also needed because macular edema reappears with the consequential visual loss. ${ }^{10}$

In another study, 20 patients with macular edema secondary to branch vein occlusion were treated with pegaptanib sodium injection with satisfactory results up to 54 weeks follow-up. ${ }^{11}$ The main outcome of the study was the efficacy of pegaptanib sodium injection in refractory macular edema due to branch vein occlusion. The uncontrolled use of nonselective anti-VEGF therapies can worsen visual acuity despite the anatomic resolution shown in OCT or FA in the longterm, because they also block the neuroprotectant isoforms of VEGF necessary for the adaptative response of retinal neurons to ischemic injury. ${ }^{12}$ That can be the reason why pegaptanib sodium has been effective, where bevacizumab or triamcinolone were not; because it has a selective action on VEGF165 (main isoform associated with angiogenesis and macular edema in ophthalmology) without blocking those isoforms necessary for the natural recovery of the retinal cells after ischemia.

Pegaptanib sodium should be further evaluated as a treatment option for macular edema associated with BRVO due to the excellent results obtained in this study.

\section{Disclosure}

The authors report no conflicts of interest in this work.

\section{References}

1. The Branch Vein Occlusion Study Group. Argon laser photocoagulation for macular edema in branch vein occlusion. Am J Ophthalmol. 1984;98:271-282.

2. Battaglia M, Saviano S, Ravalico G. Grid laser treatment in macular branch retinal vein occlusion. Graefes Arch Clin Exp Ophthalmol. 1999; 237:1024-1027.

3. Roth DB, Cukras C, Radhakrishnan R, et al. Intravitreal triamcinolone acetonide injections in the treatment of retinal vein occlusions. Ophthalmic Surg Lasers Imaging. 2008;39:446-454.

4. Patel PJ, Zaheer I, Karia N. Intravitral triamcinolone acetonide for macular oedema owing to retinal vein occlusion. Eye. 2008;22: 60-64.

5. Haller JA, Bandello F, Belfort R Jr, et al; for the Ozurdex GENEVA Study Group. Randomized, sham-controlled trial of dexamethasone intravitreal implant in patients with macular edema due to retinal vein occlusion. Ophthalmology. 2010;117:1134-1146.

6. Buchlolz PM, Buchlolz AP, Augustin AJ. Antivascular endothelial growth factor as an approach for macular edema. Dev Ophthalmol. 2010; 46:111-122.

7. Rosenfeld PJ, Fung AE, Puliafito CA. Optical coherence tomography findings after an intravitreal injection of bevacizumab (Avastin) for macular edema from central retinal vein occlusion. Ophthalmic Surg Lasers Imaging. 2005;36:336-339.

8. Figueroa MS, Contreras I, Noval S, Arruabarrena C. Results of bevacizumab as the primary treatment for retinal vein occlusions. $\mathrm{Br}$ J Ophthalmol. 2010;94:1052-1056. 
9. Campochiaro PA, Heier JS, Feiner L, et al; for the BRAVO investigators. Ranibizumab for macular edema following branch retinal vein occlusion: six-month primary end point results of a Phase III study. Ophthalmology. 2010;117:1102-1112.

10. Rabena MD, Pieramici DJ, Castellarin AA, Nasir MA, Avery RL. Intravitreal bevacizumab (Avastin) in the treatment of macular edema secondary to branch retinal vein occlusion. Retina. 2007;27:419-425.
11. Wroblewski JJ, Wells JA 3rd, Gonzales CR. Pegaptanib sodium for macular edema secondary to branch vein oclussion. Am J Ophthalmol 2010;149(1):147-154.

12. Nishijima K, Ng YS, Zhong L, et al. Vascular endothelial growth factor-A is a survival factor for retinal neurons and a critical neuroprotectant during the adaptive response to ischemic injury. Am J Pathol. 2007;171(1):53-67.

\section{Publish your work in this journal}

Clinical Ophthalmology is an international, peer-reviewed journal covering all subspecialties within ophthalmology. Key topics include: Optometry; Visual science; Pharmacology and drug therapy in eye diseases; Basic Sciences; Primary and Secondary eye care; Patient Safety and Quality of Care Improvements. This journal is indexed on

\section{Dovepress}

PubMed Central and CAS, and is the official journal of The Society of Clinical Ophthalmology (SCO). The manuscript management system is completely online and includes a very quick and fair peer-review system, which is all easy to use. Visit http://www.dovepress.com/ testimonials.php to read real quotes from published authors. 